\title{
Spectrum of rheumatologic disorders among patients attending with musculoskeletal symptoms: experience from medicine outpatient department of a tertiary care hospital of Bangladesh
} Haque $\mathrm{HF}^{\mathrm{a}}$, Ahmed $\mathrm{AKMS}^{\mathrm{b}}$, Uddin $\mathrm{KN}^{\mathrm{b}}$, Afroz $\mathrm{F}^{\mathrm{c}}$, Afroze $\mathrm{SR}^{\mathrm{a}}$, Hoque MT

\begin{abstract}
Background: Musculoskeletal conditions are prevalent and their impact is pervasive. They are one of the most common causes of long-term pain; affect hundreds of millions of people around the world; they significantly affect the psychosocial status of the affected people as well as their families and carers. This study was done to evaluate the spectrum of rheumatologic disorders among patients attending at medicine outpatient department (OPD) with musculoskeletal symptoms.

Methods: This cross-sectional study was done at OPD of Medicine, BIRDEM General Hospital from January 2014 to June 2017. All patients attending at OPD having musculoskeletal symptoms, who fulfilled criteria of definite rheumatologic disease and known rheumatologic disorders were consecutively and purposively included in this study.

Results: Total patients were 495 with female predominance (71.31\%). Mean age was 48.6 years (range 18-76 years). Among the study population majority had inflammatory joint and spine diseases (69.69\%); then degenerative joint and spine diseases (22.02\%), connective tissue diseases (2.22). Two-thirds of the patients had rheumatoid arthritis (RA) (76.23\%) among inflammatory joint and spine diseases, then ankylosing spondylitis (AS) (13.33\%).Regarding connective tissue disease, systemic lupus erythematosus (SLE) was more frequent (45.5\%). Among soft tissue rheumatism and metabolic bone disease, all study subjects had fibromyalgia (FM) and osteoporosis respectively. Rheumatoid factor was positive among two-thirds and anti-CCP antibody in twofifths of RA cases, HLA-B27 was positive in 4.3\% of AS, antineuclear antibody (ANA) and anti-ds DNA were positive in all SLE patients. Common co-morbidities were diebetes (41.4\%), ischaemic heart disease (20.6\%) and hypertension (19.1\%).
\end{abstract}

Conclusion: RA was the most common inflammatory joint disease. Degenerative diseases were the second most common condition. Common connective tissue disease was SLE.

Key words: Disease spectrum, rheumatologic disease, tertiary care hospital.

(BIRDEM Med J 2021; 11(2): 116-120)

\footnotetext{
Author information

a. Hasna Fahmima Haque, Samira Rahat Afroze, Assistant Professor, Department of Internal Medicine, BIRDEM General Hospital, Dhaka, Bangladesh.

b. AKM Shaheen Ahmed, Khwaja Nazim Uddin, Professor, Department of Internal Medicine, BIRDEM General Hospital, Dhaka, Bangladesh.

c. Farhana Afroz, Assistant Professor, Department of Respiratory Medicine, BIRDEM General Hospital, Dhaka, Bangladesh.

d. Md. Tariful Hoque, Senior Medical Officer, Dermatology, BIRDEM General Hospital, Dhaka, Bangladesh.

Address of correspondence: Hasna Fahmima Haque, Assistant Professor, Internal Medicine, BIRDEM General Hospital, Dhaka, Bangladesh. Email: drfahmimahaque @gmail.com
}

Received: November 10, 2020

Revision received: February 20, 2021

Accepted: February 28, 2021 


\section{INTRODUCTION}

Rheumatologic disorders are one of the commonest health problems with disability worldwide and cause huge public health burden. ${ }^{1,2}$ According to a report of World Health Organization, rheumatologic and musculoskeletal diseases were the second most reported cause of disability around the globe. ${ }^{3}$ The chronic complications of these diseases are responsible for high morbidity and mortality. ${ }^{4}$ It is important to know the prevalence and demography of rheumatologic diseases for assessing its burden. ${ }^{5-7}$ But the prevalence and incidence of it is variable, mostly due to environmental factors as well as ethnicity. ${ }^{8,9}$ It includes inflammatory and degenerative diseases, soft tissue rheumatism and metabolic bone diseases. ${ }^{10}$ The purpose of this study was to evaluate the spectrum of rheumatologic disorders among the patients attending at outpatient department (OPD) of medicine with musculoskeletal symptoms.

\section{METHODS}

This cross-sectional study was done from January 2014 to June 2017 at the OPD of Medicine, BIRDEM General Hospital to evaluate the spectrum of rheumatologic disorders among patients attending with musculoskeletal symptoms. All the patients having musculoskeletal symptoms with criteria of definite rheumatologic diseases and known rheumatologic disorders were included consecutively and purposively in this study. Those who did not fulfill definite criteria of any rheumatologic disease were excluded. Diagnosis of the diseases was based on American College of Rheumatology (ACR) as well as European League Against Rheumatism (EULAR) Classification Criteria, supplemented by appropriate laboratory investigations. Investigations were adjusted to the need of individual cases. Different serological tests like rheumatoid factor (RF), anti-citrullinated peptide antibody (ACPA), human leukocyte antigen (HLA)-B27, antinuclear antibody (ANA), anti-double stranded-DNA (anti-ds DNA) were done in relevant cases according to clinical diagnosis. $\mathrm{X}$-ray and magnetic resonance imaging (MRI) ofspines and joints were done where needed. All the necessary data were collected from patient's guidebook as well as OPD registry book and recorded in preformed data sheets for the purpose of this study. Data were analyzed by Statistical Package for Social Sciences (SPSS) version 20.0 for Windows and results presented in figures and tables.

\section{RESULTS}

Total study subjects were 495 . Mean age was 48.6 years (range 18-76 years) with female predominance (Figure 1). Among them majority had inflammatory joint and spine diseases $(345 ; 69.69 \%)$ followed by degenerative joint and spine diseases $(109 ; 22.02 \%)$, connective tissue diseases $(11 ; 2.22)$, soft tissue rheumatism (18; $3.64 \%$ ) and metabolic bone diseases (12;2.43\%) (Table I). Three-fourths of patients had RA (263; 76.23\%) among inflammatory joint and spine diseases, then AS (46; $13.33 \%)$, psoriatic arthritis $(15 ; 4.35 \%)$, gout $(12$; $3.48 \%)$ and reactive arthritis $(9,2.6 \%)$ (Table II). Regarding connective tissue disease, SLE (5; 45.5\%) was more frequent, then poly/dermato-myositis ( 2 ; $18.2 \%)$, systemic sclerosis (SS) $(2 ; 18.2 \%)$, mixed connective tissue disease (MCTD) $(2 ; 18.2 \%)$ (Table III). Among soft tissue rheumatism, all the subjects had fibromyalgia (FM) $(18 ; 100 \%)$ and in metabolic bone disease, $(100 \% ; 12)$ had osteoporosis. Autoimmune markers for RA, RF was positive among $(180 ; 68.44 \%)$ and anti-CCP antibody in $(104 ; 39.5 \%)$ cases, HLA-B27 for AS was positive in $(2 ; 4.3 \%)$, ANA and anti-ds DNA were positive in all SLE patients (5; $100 \%$ ), Anti-scl 70 was positive in PSS (2;100\%), antiRNP was positive in MCTD (2; 100\%) (Table IV). Common co-morbidities were DM (205; 41.4\%), IHD $(102 ; 20.6 \%)$, HTN $(95 ; 19.1 \%), \operatorname{CKD}(45 ; 9 \%)$, and hypothyroidism (20; 4\%) (Table V).

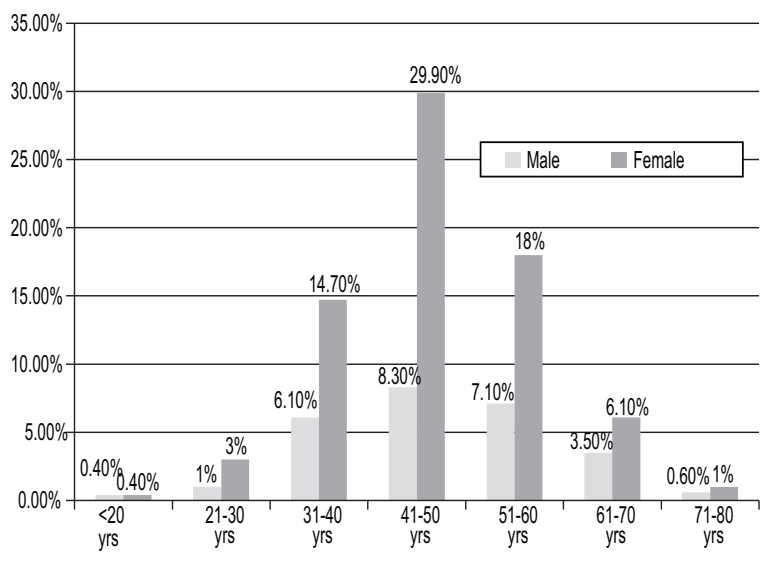

Figure 1 Age and sex distribution of patients with rheumatological diseases $(\mathrm{N}=495)$ 
Table I Distribution of patients according to disease spectrum $(\mathrm{N}=495)$

\begin{tabular}{lccc}
\hline Diagnoses & Number of patients & Percent & Sex distribution(F:M) \\
\hline Inflammatory joint and spine diseases & 345 & 69.69 & $2: 1$ \\
Degenerative joint and spine diseases & 109 & 22.02 & $1.8: 1$ \\
Connective tissue diseases & 11 & 2.22 & $10: 1$ \\
Soft tissue rheumatism & 18 & 3.64 & $8: 1$ \\
Metabolic bone diseases & 12 & 2.43 & $3: 1$ \\
\hline
\end{tabular}

Table II Inflammatory joint and spine diseases $(\mathrm{n}=345$, female 230 , male115)

\begin{tabular}{lcccc}
\hline Diagnoses & Number & Percentage & Female & Male \\
\hline Rheumatoid arthritis (RA) & 263 & 76.23 & $219(83.26 \%)$ & $44(16.73 \%)$ \\
Ankylosing spondylitis (AS) & 46 & 13.33 & $16(34.78 \%)$ & $30(65.21 \%)$ \\
Psoriatic arthritis & 15 & 4.35 & $7(46.66 \%)$ & $8(53.33 \%)$ \\
Gout & 12 & 3.48 & $3(25 \%)$ & $9(75 \%)$ \\
Reactive arthritis & 9 & 2.6 & $4(44.44 \%)$ & $5(55.55 \%)$ \\
\hline
\end{tabular}

Table III Patterns of connective tissue disease $(\mathrm{n}=11)$

\begin{tabular}{lcccc}
\hline Diagnosis & Number & Percentage & Female & Male \\
\hline Systemic lupus erythematosus (SLE) & 5 & 45.5 & $5(100 \%)$ & $0(0 \%)$ \\
Poly/dermato-myositis & 2 & 18.2 & $1(50 \%)$ & $1(50 \%)$ \\
Systemic sclerosis (SS) & 2 & 18.2 & $2(100 \%)$ & $0(0 \%)$ \\
Mixed connective tissue disease (MCTD) & 2 & 18.2 & $2(100 \%)$ & $0(0 \%)$ \\
\hline
\end{tabular}

Table IV Autoimmune markers among patients with rheumatological diseases

\begin{tabular}{llcc}
\hline Disease & Marker & Positive & Percentage \\
\hline RA $(n=263)$ & Rheumtoid factor & 180 & 68.44 \\
& Anti-CCPAb & 104 & 39.5 \\
AS $(n=46)$ & HLA-B27 & 2 & 4.3 \\
SLE $(n=5)$ & ANA & 5 & 100 \\
& Anti-ds DNA & 5 & 100 \\
PSS $(n=2)$ & Anti-scl 70 & 2 & 100 \\
MCTD $(n=2)$ & Anti-RNP & 2 & 100 \\
\hline
\end{tabular}

Table V Common co-morbidities of patients with rheumatological disorders $(\mathrm{N}=495)$

\begin{tabular}{lcc}
\hline Diagnosis & Frequency & Percentage \\
\hline DM & 205 & 41.4 \\
IHD & 102 & 20.6 \\
HTN & 95 & 19.1 \\
CKD & 45 & 9 \\
Hypothyroidism & 20 & 4 \\
\hline
\end{tabular}

\section{DISCUSSION}

Musculoskeletal (MSK) disorders are the most relevant health issuesworldwide owing to human sufferings as well as increasing social and economic burden. ${ }^{11,12}$ The prevalence of this disorders in developing countries is largely unknown. In this current study, we have tried to describe the spectrumof different rheumatologic diseases in a tertiary care hospital in Bangladesh.

In our study, demographic characteristics of patients with rheumatologic disorder revealed that the mean age 
was 48.6 with female predominance, which was almost same like different studies from different countries. ${ }^{10}$, ${ }^{13}$ The common co-morbidities were diabetes mellitus, hypertension, ischemic disease, chronic kidney disease and hypothyroidism.

According to a COPCORD study from Bangladesh, the prevalence of musculoskeletal pain was $26.3 \%$ and definite rheumatic disorders was $24.0 \%$, among them common rheumatic disorder was osteoarthritis of the knees $(7.5-10.6 \%)$ and non-specific low back pain was $(6.6-9.9 \%){ }^{14}$

However, in our study, almost two-thirds of the study subjects had inflammatory joint diseases and rest of them had degenerative joint diseases, connective tissue disease and soft tissue rheumatism, this may not reflect the true prevalence in our society, as most of our patients were diagnosed cases. Therefore, there were differences in the frequency of diseases in our study and other hospital-based studies such as retrospective study from Bangladesh, Nepal, Belgium, Iranand Nigeria. ${ }^{15-18}$ The population-based prevalence of RA is variable. ${ }^{19}$ Worldwide its prevalence is about $1 \% \cdot{ }^{19-21}$ Low incidence of RA had been described in some western studies in the last decades, especially in females with older age groups. ${ }^{22-23}$ But there was the rise of incidence in young females in developing countries. ${ }^{19,22-23}$ Our study found RA in $76.23 \%$, AS in $13.33 \%$, PsA in $4.35 \%$, gout in $3.48 \%$ and reactive arthritis in $2.6 \%$ cases among inflammatory joint diseases that was different from a previous study. ${ }^{15}$ In our study, female were predominant in RA while males were more prone to develop other inflammatory arthritis.

SLE was the most common (45.5\%) connective tissue disease and all patients were female, then the frequency of poly/dermatomyositis, systemic sclerosis and MCTD. Other studies from Bangladesh, Italy, Malaysia and Congo showed much less prevalence of SLE but females were predominant in that studies. ${ }^{15,24-27}$

Osteoporosis was present in $12 \%$ cases, which was lower than other studies from Nepal and Belgium ${ }^{16,17}$ as endocrinologists manage many osteoporosis cases. Regarding autoimmune markers for RA, two-thirds of the patients had positive rheumatoid factor and 39.5\% cases had positive Anti-CCP Ab but in AS only 4.3\% subjects had positive HLA-B27. In case of SLE, PSS and MCTD all patients had positive specific autoantibody.

\section{Limitations}

This study did not represent the prevalence among Bangladeshi population, as it was a clinic based, singlecentre study. Most patients were diabetic; whether rheumatologic disorders are similarly distributed among non-diabetic populations were not clear. Therefore, larger and multi-center survey is required.

\section{Conclusion}

In conclusion, it can be said that, this study has shown variability among the different rheumatic diseases and its burden in different age groups and genders along with co morbidities. Among musculoskeletal disorders, inflammatory joint diseases were the most common rheumatologic disease followed by degenerative joint disease and connective tissue disease. Regarding common co morbidity, diabetes was in the upmost position.

Authors' contribution: HFH planned the research, searched literature, analyzed data and drafted the manuscript. AKMSA, KNU, FA, SRA revised the manuscript. MTH collected data. All authors read and approved the final version of the manuscript for submission.

Conflict of interest: Nothing to declare.

\section{REFERENCES}

1. Gran JT. The epidemiology of chronic generalized musculoskeletal pain. Best Pract. Res. Clin. Rheumatol 2003;17(4):547-56.

2. Yelin E, Cisternas M, Pasta D,Trupin L, Murphy L, Helmick CG.Medical careexpenditures and earning losses of persons with arthritis and otherrheumatic conditions in the United States in 1997:total andincremental estimates. Arthritis Rheum 2004;50:2317-26.

3. Vos T, Flaxman AD, Naghavi M, Lozano R, Michaud C, Ezzati M, et al. Years lived with disability (YLDs) for 1160 sequelae of 289 diseases and injuries 1990-2010: a systematic analysis for the global burden of diseasestudy 2010. Lancet 2012; 380:2163-96. 10.1016/S01406736(12)61729-2.

4. Mohsin Z, Asghar A A, Faiq A, Khalid I, Haque IU, Rehman $\mathrm{S}$, et al. Prevalence of Rheumatic Diseases in a Tertiary Care Hospital of Karachi. Cureus2018;10(6): e2858. DOI 10.7759/cureus.2858.

5. Lawrence RC, Hochberg MC, Kelsey L, McDuffie FC, Medsger TA, Felts WR, et al. Estimates of the prevalence of selected arthritis and musculoskeletal diseases in the United States. JRheumatol 1989;16:427-41. 
6. Taylor W,Smeets L, Hall J, McPherson K. The burden of rheumatic disorders in general practice: Consultation rates for rheumatic disease and therelationship to age, ethnicity, and small-area deprivation. N Z Med J 2004;117:U1098.

7. Suarez-Almazor ME. High burden of rheumatic disease in Mexico: A comprehensive community based epidemiologicalstudy. J Rheumatol 2011;38:8-9.

8. Fessel WJ.Epidemiology of systemic lupus erythematosus. Rheum DisClin North Am 1988;14:15-23.

9. Chifflot H, Fautrel B, Sordet C, Chatelus E, Sibilia J. Incidence andprevalence of systemic sclerosis: a systematic literature review. SemArthritis Rheum 2008, 37:223-35.

10. OguntonaSA,Edunjobi AS,Olatunde AO.Prevalence of rheumatic diseases in a rheumatology outpatient practice of a tertiary hospital.International Research Journal of Medicine and Biomedical Sciences April 2016;Vol.1 (2);11-8.

11. Cisternas MG, Murphy LB, Yelin EH, Foreman AJ, Pasta DJ, Helmick CG.Trends in medical care expenditures of US adults with arthritis and otherrheumatic conditions 1997 to 2005. J Rheumatol, DOI. 2009. https://doi.org/ 10.3899/jrheum.081068.

12. Yelin E, Murphy L, Cisternas MG, Foreman AJ, Pasta DJ, Helmick CG. Medical care expenditures and earnings losses among persons with arthritis and other rheumatic conditions in 2003, and comparisons with 1997. Arthritis Rheum.2007. https://doi.org/10.1002/art.22565.

13. Ahsan T, Khowaja D, Jabeen R, Erum U, Ali H, Farooq MU, Rehman UL. Burden of rheumatological disorders in a tertiary care hospital. J Pak Med Assoc. 2016 May; 66(5):563-7.

14. Haq SA, Darmawan J, Islam MN,Uddin MZ, Das BB, Rahman F, et al. Prevalence of rheumatic diseases and associated outcomes in rural and urban communities in Bangladesh: a COPCORD study. J Rheumatol 2005 Feb;32 (2):348-53.

15. Ahmed AKMS, Rahim M A, Dewan P, Haque H F, Nazim R F, Afroz Fet al. Spectrum of Rheumatological Disorders: A Clinic-based Study. Journal of Medicine 2014;15(1): 23-7.

16. Das RN, Paudel R. Spectrum of rheumatological disorders: an experience of 337 cases in a tertiary care hospital in Pokhara valley, Nepal. APLAR Journal of Rheumatology 2006;9:248-56
17. Vanhook J, Decerck K, Geusens P. Prevalence of rheumatic diseases in a rheumatological outpatient practice. Ann Rheum Dis 2002;61:453-5.

18. Bagher OM, Golbarg M, Hossein S. Pattern of rheumatic diseases in two outpatient clinics in Iran: similarities with some different features. Indian J Med Sci 2011 Jan; 65(1): 7-17.

19. Oguntona SA, Edunjobi AS, Olatunde AO.Prevalence of rheumatic diseases in a rheumatologyoutpatient practice of a tertiary hospital.Int Res J Med Biomed Sci 2016,1:11-8.

20. Abdel-Nasser AM, Rasker JJ, Valkenburg HA. Epidemiological and clinical aspects relating to the variability of rheumatoid arthritis. Seminars in Arthritis and Rheumatism 1997 Oct;27(2):123-40.

21. Alamanos Y, Voulgari PV, Drosos AA. Incidence and prevalence of rheumatoid arthritis, based on the 1987 American College of Rheumatology criteria: a systematic review. Semin Arthritis Rheum 2006 Dec;36(3):182-8.

22. WHO Scientific Group on the Burden of Musculoskeletal Conditions at the Start of the New Millennium. (ý 2003 : Geneva, Switzerland)ý. (ý2003)ý. The burden of musculoskeletal conditions at the start of the new millenium : report of a WHO scientific group. Geneve : World Health Organization. https://apps.who.int/iris/ handle/10665/42721.

23. Mody GM. Rheumatoid arthritis and connective tissue disorders: sub-Saharan Africa. Baillière's Clinical Rheumatology 1995;9: 31-44.

24. Al Hasan, S., Rahim, M., Siddiq, M., Hossain, M., Taslim, A., Paul, S., et al. Study of Spectrum of Rheumatic Diseases in the Department of Physical Medicine \& Rehabilitation, Chittagong Medical College Hospital, Bangladesh. Journal of Chittagong Medical College Teachers' Association 2009;20(1), 6-11.

25. Cimmino MA,UgoliniD, Cauli A, Mannoni A, Macchioni P, Ciocci A, et al. Frequency of musculoskeletal conditions among patients referred to Italian tertiary rheumatologicalcenters. Clinical and Experimental Rheumatology 2006;24:670-6.

26. Chin GL.Shukor AB.The spectrum of rheumatic diseases seen at the Rheumatology Clinic, University Kebangsaan Malaysia. Med J Malaysia 1988;43:297-301

27. Malemba JJ, Mbuyi-Muamba JM. Clinical and epidemiological features of rheumatic diseases in patients attending the university hospital in Kinshasa. Clin Rheumatol 2008;27:47-54. 